\title{
New recommendations for food-based dietary guidelines for healthy eating in Ireland
}

\author{
N. M. Devaney, C. M. O’Brien, S. J. Burke and M. A. T. Flynn \\ Food Safety Authority of Ireland, Lower Abbey Street, Dublin 1, Republic of Ireland
}

Evaluation of Ireland's food guide to healthy eating concluded that guidance on energy requirements for different age and gender groups needs to be included in the newly revised dietary guidelines ${ }^{(1)}$. This approach requires more specific and quantitative advice on appropriate food choices.

Energy goals were set according to age and gender requirements at sedentary and moderate activity levels. Well-established goals for macronutrients ${ }^{(2)}$, fibre ${ }^{(3,4)}, \mathrm{Fe}^{(5)}, \mathrm{Ca}^{(6)}$ and vitamin $\mathrm{D}^{(6)}$ were set. An iterative approach was used to develop 22 4-day food intake patterns that would meet these goals for males and females representing different age groups (5-12 years, 13-18 years, 19-50 years and $51+$ years). Input from dieticians specialising in pediatrics and geriatrics was incorporated to ensure the food intake patterns were appropriate.

Energy intakes were achieved within $0.04 \mathrm{MJ}$ of the energy goals. Total fat provided 26-35\% energy; saturated fat provided 8-11\% energy and non-milk extrinsic sugar intakes were below $10 \%$ energy ${ }^{(7)}$. Fibre goals were achieved except for women with lower energy requirements $(\leq 8.1 \mathrm{MJ})$. Fe reached estimated average requirements (EAR) for all meal patterns. Adequate intakes for Ca were reached, except for 9-10 year olds who have a high requirement $(1300 \mathrm{mg} / \mathrm{d})$ relative to their energy needs. Vitamin D intakes remained inadequate for all age and gender groups.

The table shows the recommended number of servings required from each of the major food groups to achieve a healthy diet. Setting energy requirements for sedentary levels of activity was deemed inappropriate for children.

\begin{tabular}{|c|c|c|c|c|c|c|c|c|}
\hline \multirow{2}{*}{$\begin{array}{l}\text { Age } \\
\text { Gender }\end{array}$} & \multicolumn{2}{|c|}{$5-13$ years } & \multicolumn{2}{|c|}{$14-18$ years } & \multicolumn{2}{|c|}{$19-50$ years } & \multicolumn{2}{|c|}{$51+$ years } \\
\hline & Males & Females & Males & Females & Males & Females & Males & Females \\
\hline Energy range $(\mathrm{MJ})^{*}$ & $5.9-9.2$ & $5.9-8.4$ & $10-11.7$ & 8.4 & $10-10.9$ & $8.4-9.2$ & $9.2-10$ & 7.5 \\
\hline \multicolumn{9}{|l|}{ Bread cereals, etc. } \\
\hline Moderately active & $3-5$ & $3-4$ & $5-7$ & 4 & $5-7$ & $4-5$ & $4-5$ & $3-4$ \\
\hline Sedentary & & & $4-5$ & 3 & $4-6$ & $3-4$ & 4 & 3 \\
\hline Fruit and vegetables & 5 & 5 & $5-6$ & 5 & $5-7$ & $5-6$ & 5 & 5 \\
\hline Dairy foods & $3-5$ & $3-5$ & 5 & 5 & $3-5$ & 3 & 3 & 3 \\
\hline \multicolumn{9}{|l|}{ Meat and alternatives } \\
\hline Main meal & 1 & 1 & 1 & 1 & 1 & 1 & 1 & 1 \\
\hline Light meal & $1-2$ & 1 & 1 & 1 & $1-2$ & 1 & 1 & 1 \\
\hline
\end{tabular}

*Estimated energy requirements for sedentary and moderate levels of physical activity were based on the Institute of Medicine (IOM) Dietary Reference Intakes report 2002 for 'referenced sized individuals'. 'Reference size' as determined by IOM is based on the median height and weight for age up to 18 years of age and median height and weight for that height to give a BMI of 21.5 for adult females and 22.5 for adult males.

Qualitative recommendations were also included in the newly revised dietary guidelines. Sugar and preserves should only be sparingly used to make high-fibre cereals and breads more palatable. Other foods such as cake, confectionery, soft drinks, etc., should be limited to occasional use. Finally, a daily supplement of vitamin D is recommended for everyone living in Ireland $(5 \mu \mathrm{g}$ for $5-50 \mathrm{years}, 10 \mu \mathrm{g}$ for $51+$ years $)$.

1. McFeely et al (2010) Proc Nut Soc (submitted).

2. Institute of Medicine (2002). Washington DC: National Academy Press.

3. Irish Heart Foundation (2007). Dublin: Irish Heart Foundation.

4. Williams CL et al (1995). Pediatrics 96, 985-988.

5. Nordic Nutrition Recommendations (2004). 4th Ed. Nordic. Denmark.

6. Institute of Medicine (2006) Washington DC: National Academy Press

7. COMA (1997) Report on Health and Social Subjects 41. London: HMSO. 